\title{
FREEFORM ARCHITECTURE DESIGN AND CONSTRUCTION PROCESS USING CONSTRUCTION IT
}

\author{
Dae Geon Kim \\ Professor, Department of Architectural \& Civil Engineering, \\ Dong-seo University, Korean \\ Gun43@hanmail.net
}

\begin{abstract}
In recent years, freeform architecture is rapidly developing, and it is being designed and constructed by various techniques using construction convergence technologies such as IT. Such freeform building structure systems are steadily increasing not only in Korea but also all over the world. The purpose of this study is based on BIM (Building Information Modeling) technology through 3D interface, which is based on the integrated management system of the design, construction and maintenance process of freeform architecture. The BIM module is made up of 4D models that are more easily combined with the process and is considered to contribute to shorter construction periods, better quality, and lower costs by minimizing errors due to efficient manpower management and on-site construction. Therefore, this study aims to develop an IT design and construction process and management integrated system that can implement various freeform architectural designs and to develop technologies that operate them efficiently.
\end{abstract}

Keywords - Freeform Architecture, Construction Process, BIM, construction IT, integrated management system

\section{INTRODUCTION}

Recently, the expression of freeform architecture is mainly implemented through building exterior materials, and there is a lack of research on a series of process processes from design stage to construction in order to optimize construction in the field. The stepby-step process performed to construct the freeform building exterior is followed by the step-by-step process for implementing and optimizing 3D modeling simulation considering the constructability and economic feasibility [1]. In particular, precise construction through lifting and surveying in the field is an important process to secure the quality of the final finished product, which is a key element to be managed by the structure and material technology. The use of digital technology in the architectural field has been extended from the use for early architectural 2D drawing schemes to tools for form creation and visualization, and 3D modeling. In particular, as the CAD system shifted from 2D to 3D, solid modeling, non-uniform Rational B-Spline (NURBS), polygon, metaclay system, and Lattice Deformation Modeling enabled the reproduction of freeform architecture. As a result, the transformation of nonlinear spatial thinking could be realized. The architect's desire for freeform architecture due to the transition to a nonlinear paradigm had limitations that could not be reproduced by existing CADs.

As a solution to this problem, Non-Uniform Rational B-Spline (NURBS) and 3ds Max, Maya, and Rhino, which provide polygon modeling methods, were used to create and 
reproduce the shape of the architecture. Although it played a role in facilitating the formation, reproduction, and visual understanding of these architectures, it was necessary to secure 3D building data that can be used to build not only the reproduction of architecture but also the construction of large-scale and freeform architectures. This falls short of the architect's demand for creating freeform forms. In the field of architecture, CATIA was first used by architect Frank O. Gehry, who was looking for a CAD system to reproduce his freeform architecture. Initially, it was used partly for the construction of digital data and construction members for construction.

Since then, along with 3D CAD systems, digital production technologies have been developed to overcome the limitations of construction technology, such as 3D scanners and automatic CNC (Computerized Numerical Control) CAD / CAM techniques. In particular, for complex types of architectures where design, construction, structural calculation and component production are difficult without 3D data, digital data sharing and transmission is paramount for efficient material production and construction. Therefore, in order to construct data capable of accurate data generation and quick integration information extraction for construction and member manufacturing, integrated data formation with BIM system should be possible. This means that the freeform shape information formed should be capable of transition to BIM data.

\section{FREEFORM BUILDING DESIGN PROCESS}

The design process of a freeform building must proceed to shape complex structures by covering various geometric patterns in the working area of architectural design. From the concept of the freeform process, the process is divided into three stages as shown in Table I, from the concept of the drawing to the stage in which the intended complex form is actually constructed while maintaining the form of controllable data.

Table I. Design process for ragged buildings

\begin{tabular}{|l|l|l|l|}
\hline \multirow{2}{*}{$\begin{array}{l}\text { Freeform Building } \\
\text { Design Process }\end{array}$} & $\begin{array}{l}\text { Design concept } \\
\text { Materialize design } \\
\text { concepts through } \\
\text { expression media }\end{array}$ & $\begin{array}{l}\text { Final design to meet } \\
\text { design requirements }\end{array}$ & $\begin{array}{l}\text { Description in drawing form } \\
\text { for practical construction }\end{array}$ \\
\cline { 2 - 4 } & Planning Design & $\begin{array}{l}\text { Planning } \\
\text { Basic design }\end{array}$ & Detailed design \\
\hline
\end{tabular}

\subsection{DESIGN CONCEPT}

It is an early stage of creative ideas and collects data through drawings, images, photographs, diagrams, models, statistics and analysis. Through these various expression media, the design concept virtually existing within the designer's thinking system is embodied as an appropriate media. These design concepts are included in the planning for development and reproduction. These design concepts are included in the planning for development and reproduction.

\subsection{DESIGN DEVELOPMENT}

It is the process of covering both planning and basic design by reviewing the appropriate alternatives that satisfy the design requirements such as site, use, program, scale, and space through design media and deciding the final design. 


\subsection{REAPPEARANCE}

The final design is described in the form of drawings defined by symbols and dimensions necessary for actual construction through the process of reproduction in which the final design is converted to have specific properties. This is the process of implementation design of the design.

\section{CONSTRUCTION IT TECHNOLOGY}

As accurate freeform members can be manufactured, freeform construction has become more feasible. It is possible to transmit accurate member data using digital technology, and furthermore, more precise and accurate manufacturing and construction are possible by applying CNC technology that directly uses member data for manufacturing. As shown in Fig 1, an early example of the accurate fabrication of parts by digital technology is the use of 3D digital model data from Kunsthaus Gras (2002) for the creation and manufacture of skin materials. P \& C Department Store (2005) implemented a double curvature curved surface using digital models, and calculated and produced accurate quantities for the construction of double curved wooden beams and 6 500 glass panels. In practice, however, due to budgetary problems, double curvature surfaces have been replaced with rectangular flat glass panels. In addition, BMW Welt (2007) created a complex form of glass and stainless steel panels, which are annular outer shell materials of the double cone, using a 3D digital model, and created an extraction plan. In the Innsbruck Historic Entrance (2007), 2,500 PE members connecting the steel rib structure and the outer panel were generated by a 3D digital model. In Water Cube (2008), 3D model formation enabled 4000 various bubble structures (maximum bubble $7.5 \mathrm{~m}$ ) in the envelope space, size adjustment of members and generation of details. At the EPFL Learning Center (2008), digital data was used to create formwork for the construction of large double-curved concrete slabs. The Experience Music Project is an example of creating a curved frame (steel beam) using a 3D digital model (CATIA).

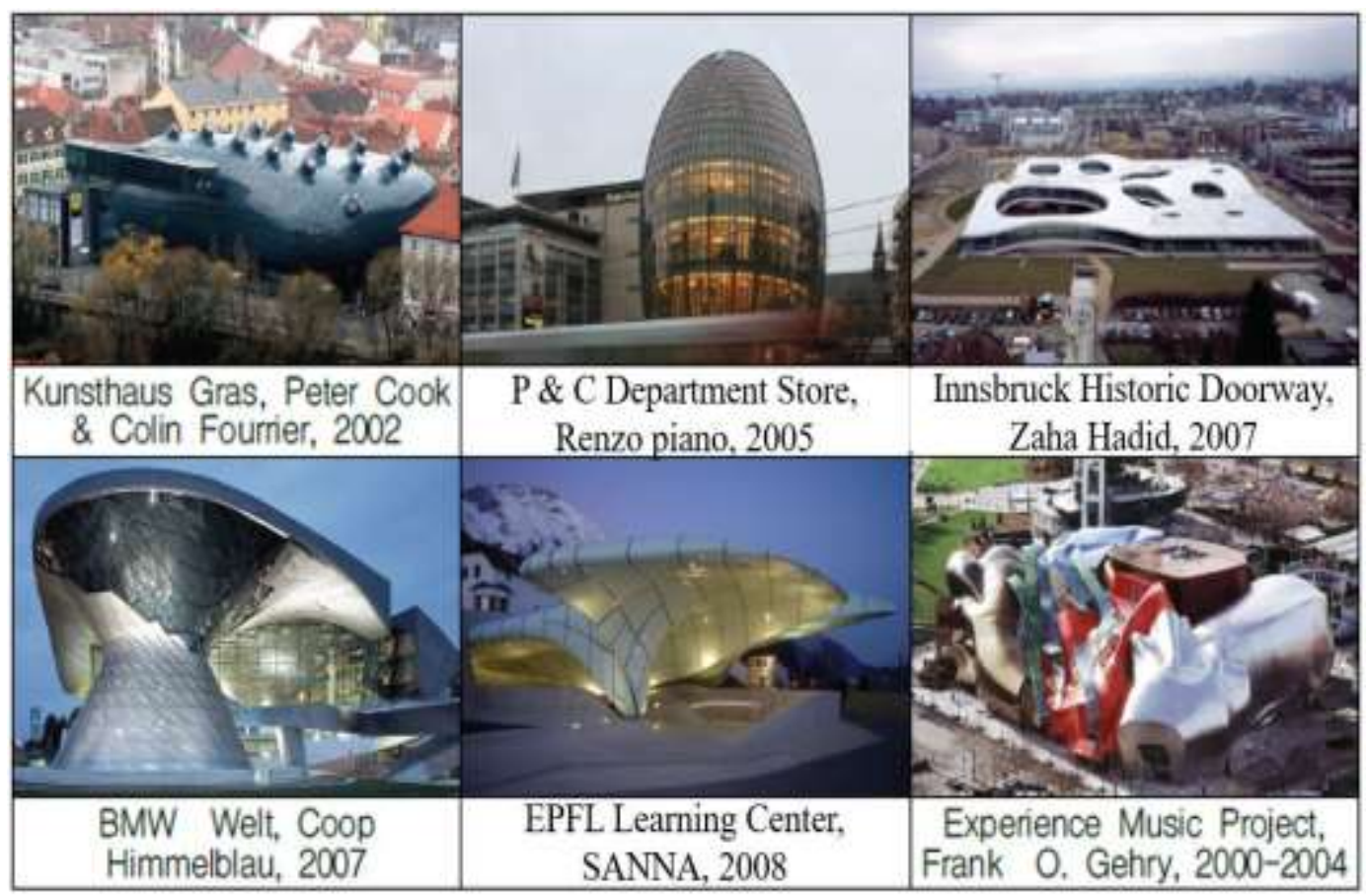

Fig. 1 Fabrication of freeform structural members using BIM 
In addition to the data transfer and drawing generation necessary for the production of parts, a method of manufacturing a part by direct data transfer with a CNC machine has been introduced. In this case, there is a limit to only the absence of a range that the CNC machine can accept, but it is a technique that has significant advantages in accuracy, and its application projects are still increasing [4]-[6]. Freeform building projects are an important factor in ensuring effective building systems and reasonable building periods and costs. In particular, as shown in fig 2, the unstructured structure designed through BIM design-based 3D simulation needs to be manufactured through networking in connection with factory manufacturing. In addition, automated manufacturing systems for supplying pre-fabricated materials, including schedule management and factory-made non-structured concrete, are the core values of supply chain management (SCM), including the right time, the right price, the right goods, the right quantity and the right place. It is introduced via air and then transported to the site [7].

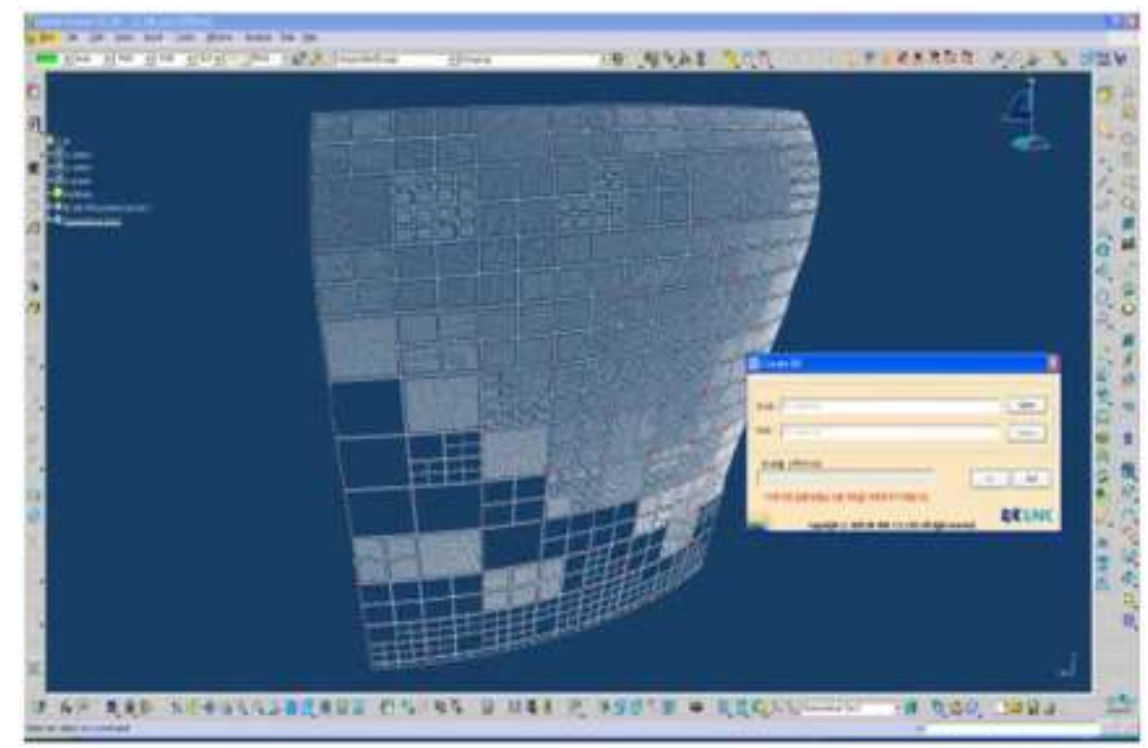

Free-Form design design through 3D simulation program
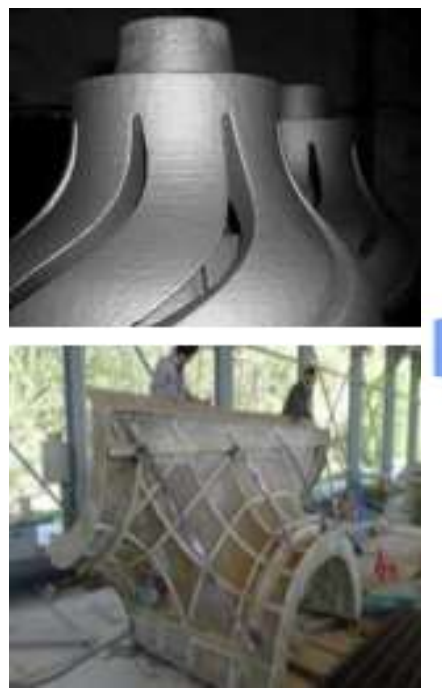

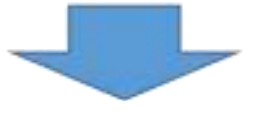

MACHINING
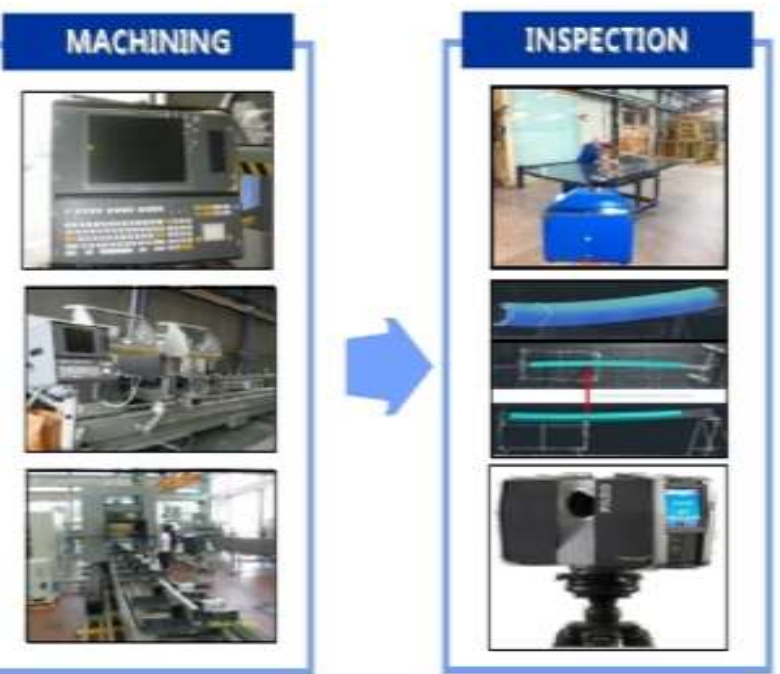

Fig. 2 BIM-based 3D design and factory production process of freeform structures 
In construction, digital technology was first used to make and visualize 2D drawings and then was extended to make 3D models for non-formed buildings material it is now applied even to production and maintenance of non-formed building materials. As such, an automated design and production system is developed by sending a double curve as a form of data to a CNC machine using a digital model such as fig 3 .

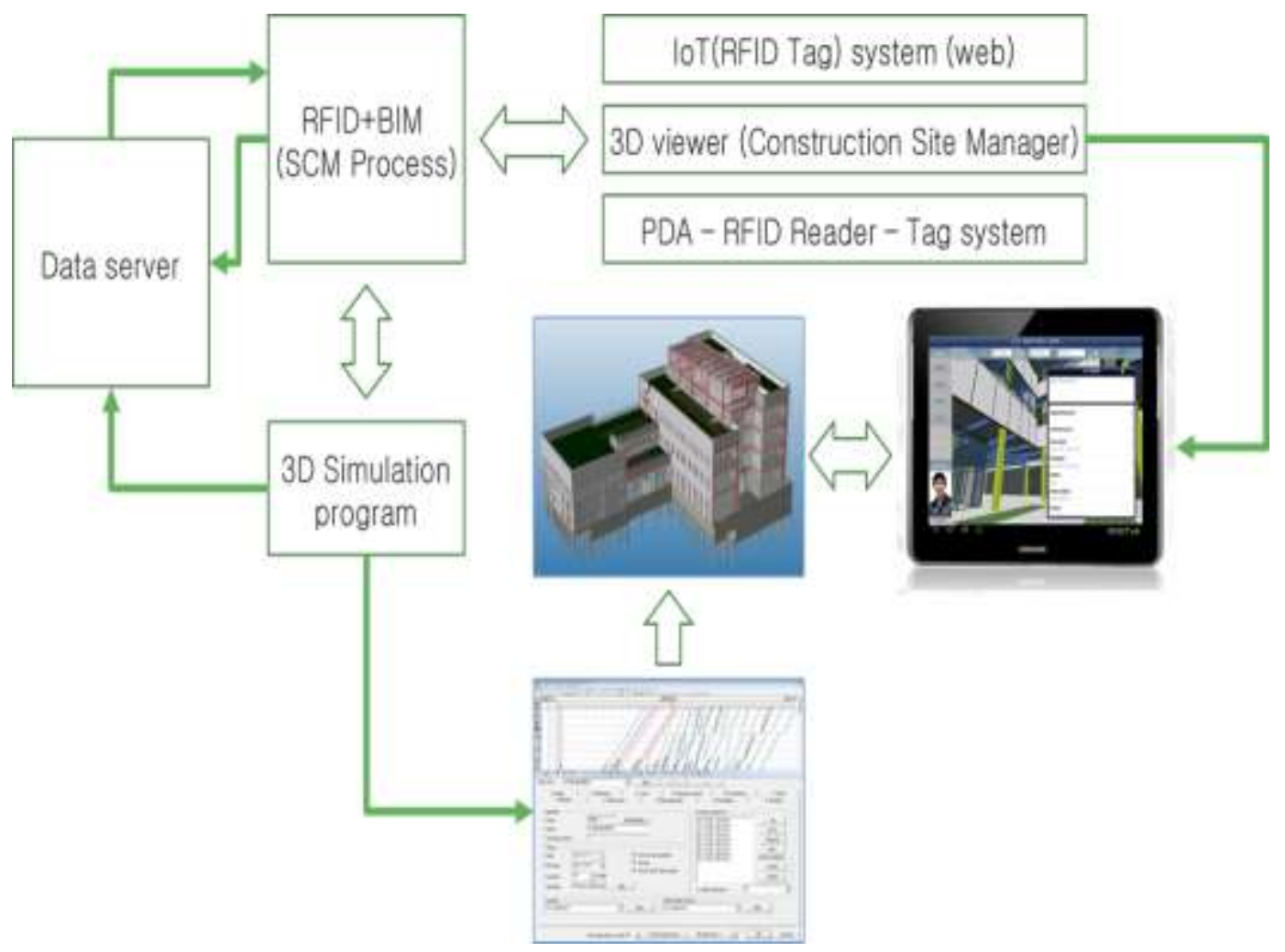

Fig. 3 RFID transport process using materials and IoT for manufacturing freeform buildings

In addition, for the design of a member, a management process through which the information collected from the tags attached to each member using the Building Information Modeling(BIM) technology for the 3D spatial design and a mobile-based Radio Frequency Identification(RFID) reader can be checked is developed. Through this, any waste factors including a delay in reflecting information caused by a non-formed construction material such as a precast concrete can be resolved, and precise construction management can be achieved by applying the concept of real-time production and materials management used in the IT distribution system [8].

Breaking away from the conventional distribution system including the old wired operation method and these parated web system and delayed reflection of information, the process of a new IT convergence system is illustrated in fig 4 [9]. To utilize the real-time information collected and managed from RFID tags and on the web system based on the information extracted from a BIM, IDs of precast concrete members are stored on the webserver and can be managed in real time by processing the geometric information by ID in a batch using a IT program used for a web game.

In addition, a real-time 4D simulator was developed as shown in fig 3 to reflect any changes in information in real time, and a solution that enables a BIM module to be used as $\mathrm{CAD}$ and $3 \mathrm{D}$ simulation program was also developed. Figure 4 illustrates the composition of functions of the 4D simulator, a 4D model composed using a IT program. Figure 4 is a web-based 4D simulator, which illustrates a construction process simulation using a web system based on an IT convergence system of BIM and RFID tag 
technologies [10]-[15]. In particular, a cloud-based web system was built in order to link the web-based IT process to a mobile phone from a precast concrete, creating a significant improvement in efficiency so that site managers and constructors can check transported quantity and the installation process simultaneously. A quantitative analysis of the efficiency of the system was performed as indicated in terms of the time taken to search information, construction simulation and the time taken to reflect web data [16].
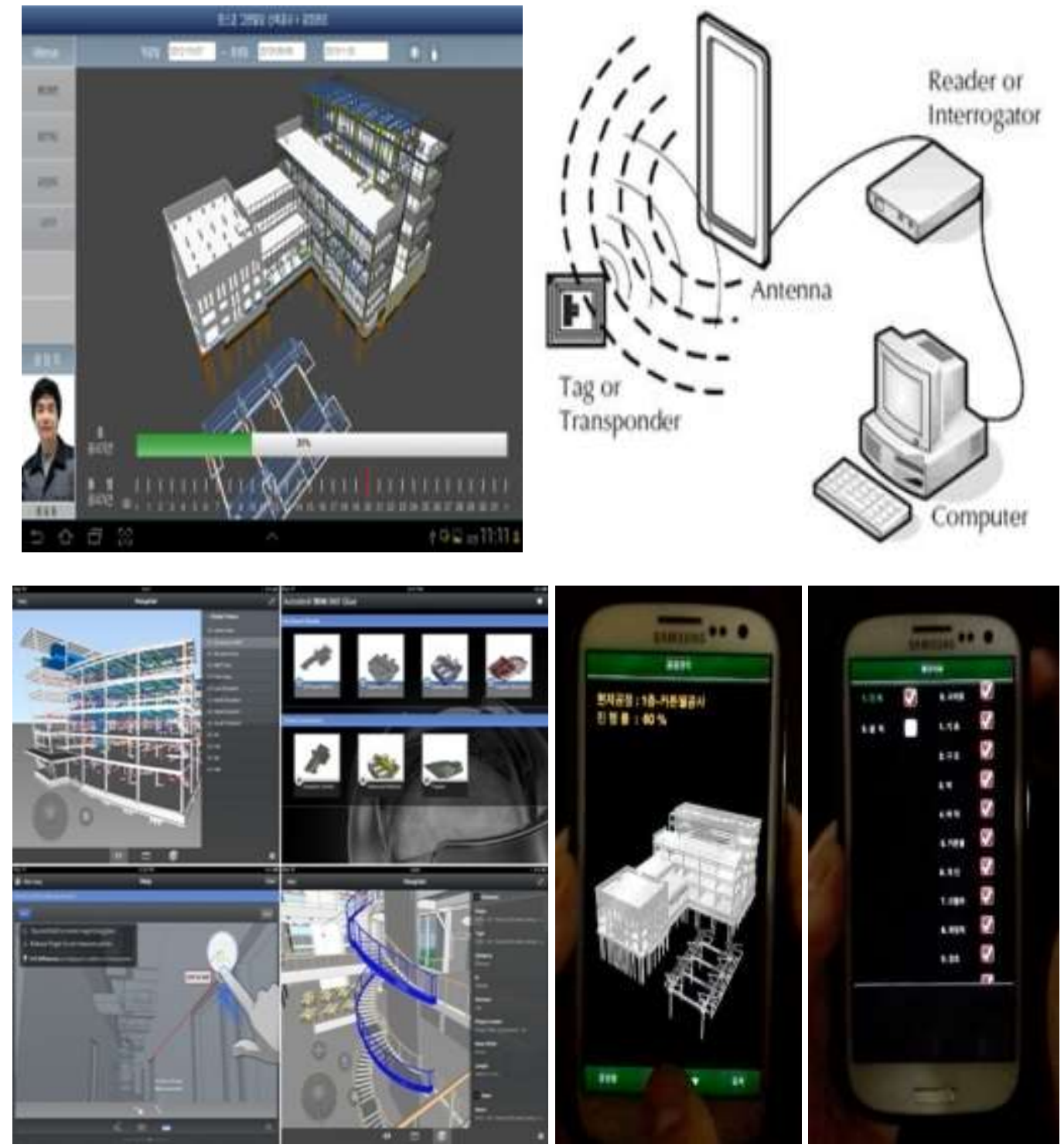

Fig. 4 Web system based on an IT convergence system of BIM and RFID tag technologies

\section{CONSTRUCTION PROCESS OF FREEFORM ARCHITECTURE}

In this study, the process of dividing the optimized construction to realize the freeform building by the process from the design stage was set up and the process is shown in Figure 5. 

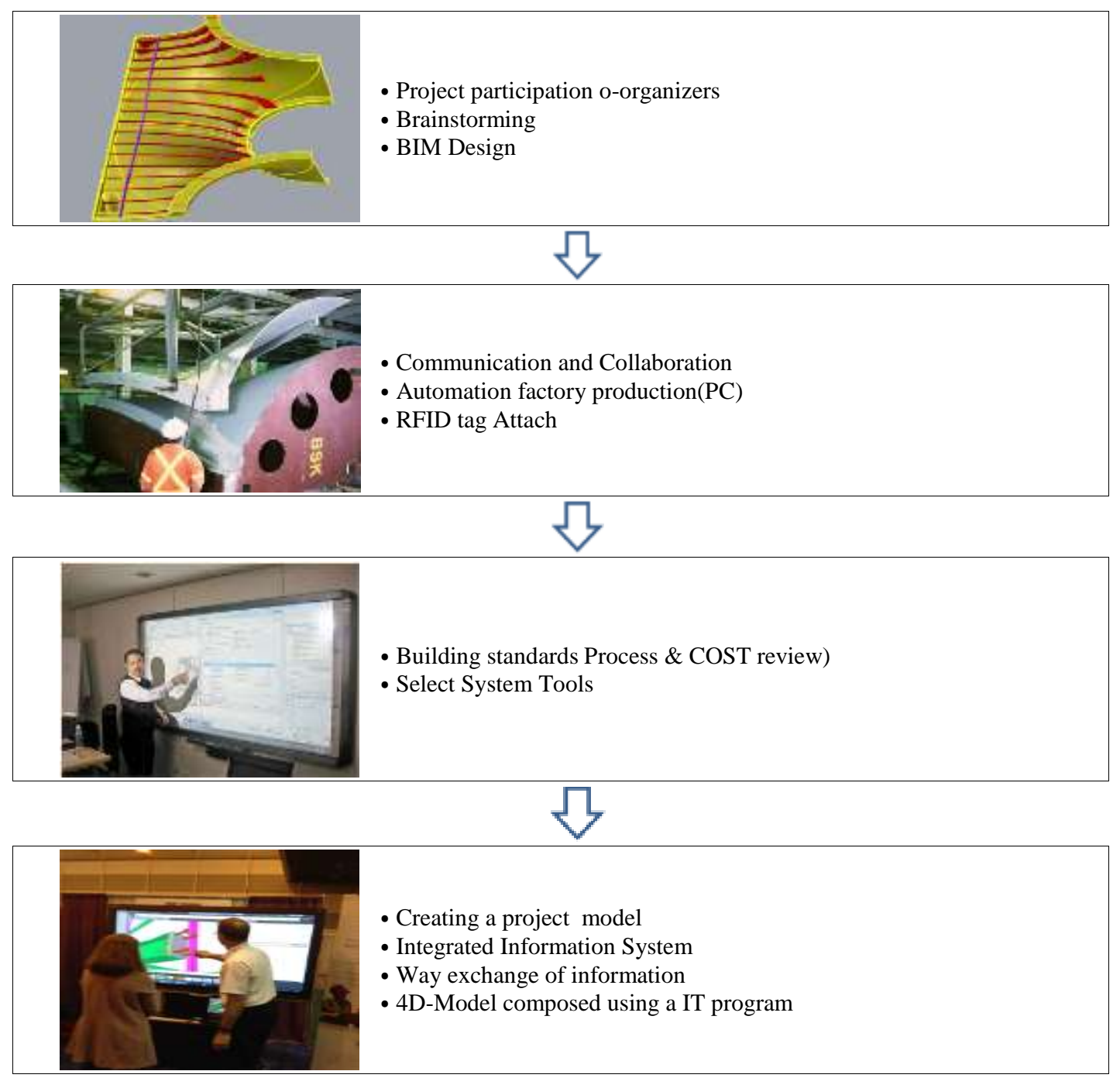

- Creating a project model

- Integrated Information System

- Way exchange of information

- 4D-Model composed using a IT program

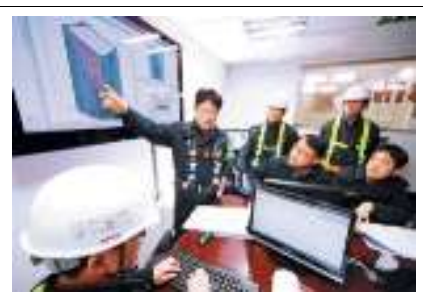

- Each process segment operating plan established

through collaboration between participants

- Application Process

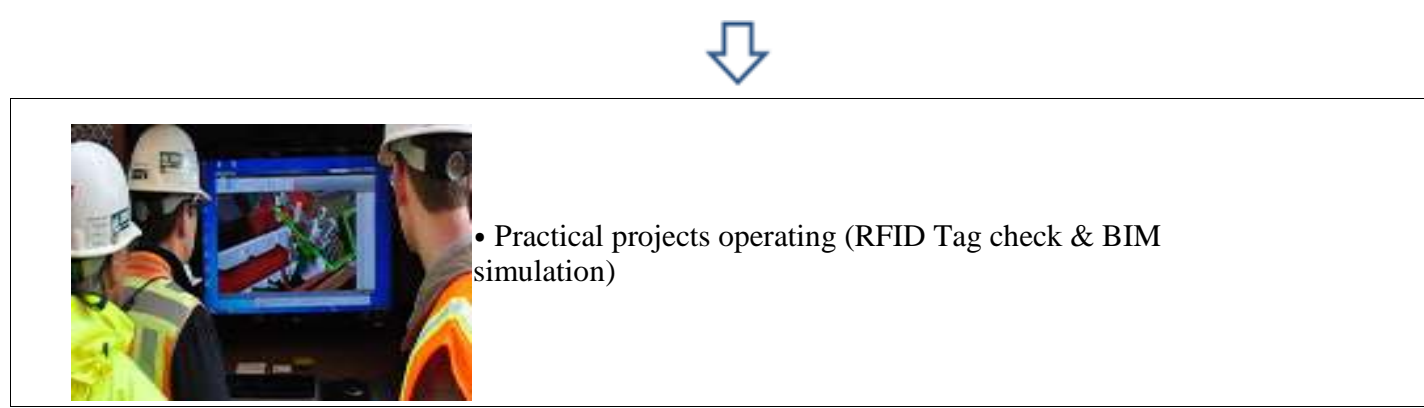

Fig. 5 construction process of freeform architecture 


\section{DEVELOPMENT OF FREEFORM BUILDING ELEMENT TECHNOLOGY}

\subsection{DEVELOPMENT OF FREEFORM BUILDING EXTERIOR PANELS}

The production of exterior panels of freeform buildings is divided into four stages, as shown in fig 6. It is divided into mold assembly, concrete pouring and curing. After assembling the shape control agent, remove dust and foreign material on the surface by using a torch as shown in the picture(Shape control agent installation) to remove various foreign materials to secure the adhesion of the shape control agent before installation in the mold. Thereafter, steam curing increases the strength of the structure [17]. Freeform exterior panels must have an ultra-high strength of $130 \mathrm{MPa}$ or more to prevent deformation of the structure. Therefore, to secure ultra high strength of $130 \mathrm{MPa}$ or more, steam curing is required to increase the curing temperature of concrete to promote the hydration reaction.

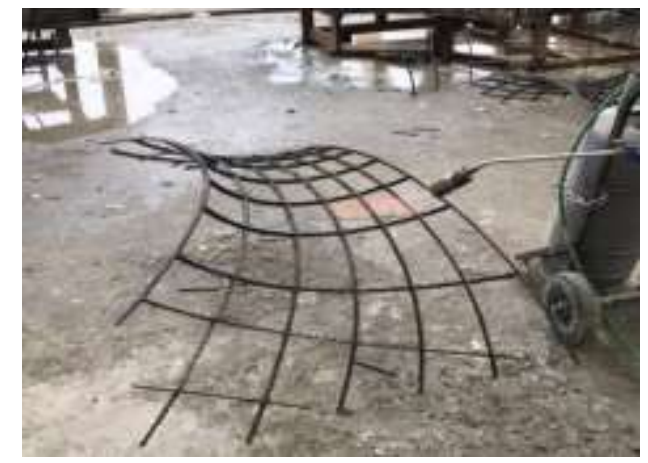

[Shape Control Assembly]

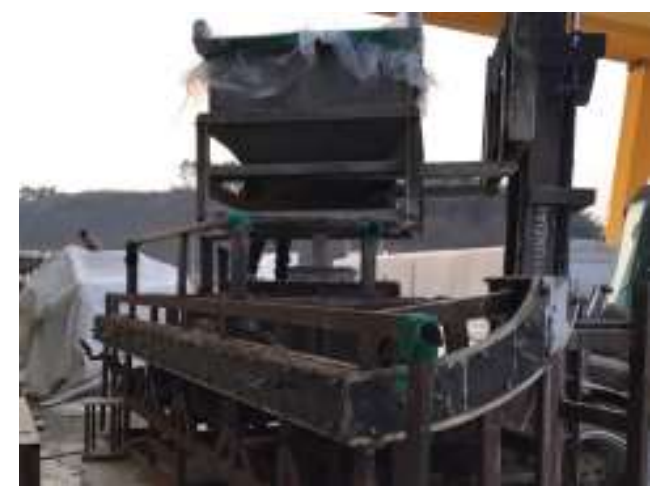

[Concrete pouring]

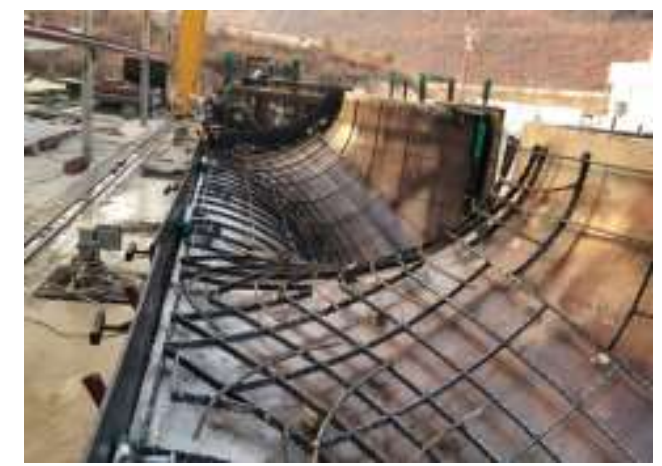

[Shape control agent installation]

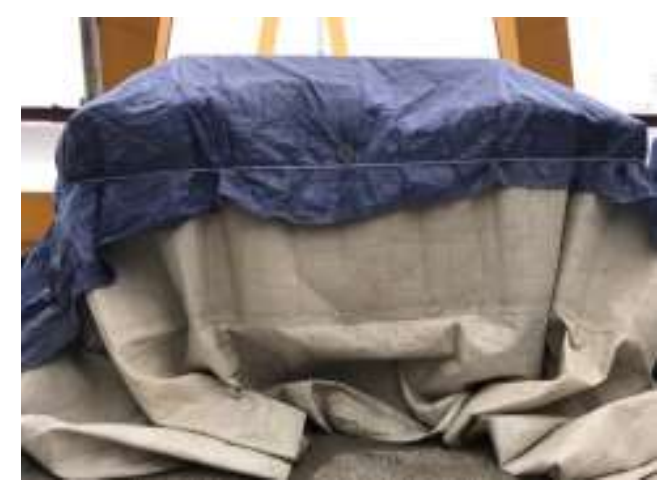

[Steam Curing]

Fig. 6 How to make exterior panels of freeform buildings

The process control plan for the freeform building panel is shown in figure 7. First of all, shop DWG is produced through 3D modeling and simulation of shape is performed. After that, finish in the order of preliminary review on joints and details. 

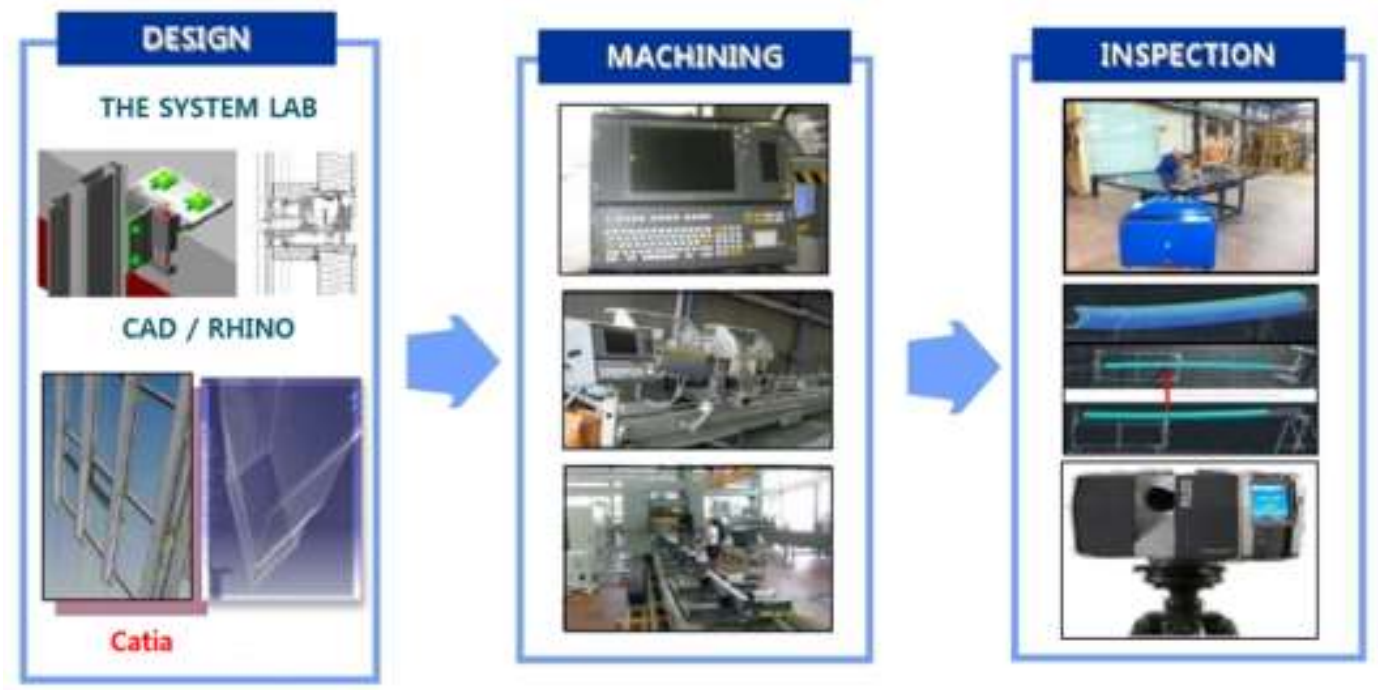

Fig. 7 Process control plan of freeform building panel

\section{CONCLUSIONS}

In this study, the step-by-step process and efficient plan for freeform architecture were studied. In the design phase, the utilization of the unstructured structure was studied through the BIM program of 3D simulation using IT. An automated program was used to systematically construct a production system for unit module panel structures in freeform architecture. In addition, the study was carried out to secure stable quality by subdividing the process for optimal construction of freeform architecture into each process step. In particular, the use of non-structural building materials, such as precast concrete manufactured in factories, has established IT convergence technology to realize the efficiency of material distribution, building process and management. In addition, in the process of applying IT technology to the construction industry, BIM modules can be more easily constructed into 3D model. Through RFID system, information can be reflected in real time for efficient manpower management and field management. By constructing such a system, efficient buildings of freeform structures can be completed by minimizing design and construction errors.

The study of freeform building structures involves a complex construction process of IT and manufacturing technology, which is different from the general structure. It is possible to secure the quality of freeform structures through the convergence technology incorporating these design and construction stages. The result of this study will be an important data to solve the problems that may occur in the construction of the freeform building in the actual site.

\section{REFERENCES}

[1] Kim We Gon. "Green Revolution." Korea Institute of Building Construction, 3 edition vol.35 (2009): 57.

[2] Kwon Choon Ahn. "Analysis of system development demands to optimize computer application of architectural work management." Korea Institute of Building Construction 11 edition vol.6 (2011): 567576

[3] Kim Ja Yeon. "Research on the actual condition and awareness degree of time shortening. " Korea Institute of Building Construction, 10 edition vol.5 (2010): 87-95

[4] Nourah A. Almubarak, Anwar Alshammeri, Imtiaz Ahmad, "Automata Processor Architecture and Applications: A Survey", International Journal of Grid and Distributed Computing, NADIA, ISSN: 2005-4262 (Print); 2207-6379 (Online), vol.9, no.3, April (2016), pp. 53-66.

[5] Li Sun, Ying Liu, Qiang Qu, Lilin Ma, Guang Yang and Hu Cao, "Research on Construction of Enterprise Informatization based on Model of Multi-agent RigidFormation", International Journal of 
Grid and Distributed Computing, NADIA, ISSN: 2005-4262 (Print); 2207-6379 (Online), vol.7, no.6, December (2014), pp. 129-136.

[6] National IT industry Promotion Agency. "Construction and IT convergence technologies Roadmap", Technology Trends Weeks Vol. 1390 (2009)

[7] Bo Yu, Zhongliang Guan, Yan Jiang, Cuiyu Qi, Shifeng Liu, "The "Container-Cloud" Architecture and Scene Perception in IoE Era", International Journal of Grid and Distributed Computing, NADIA, ISSN: 2005-4262 (Print); 2207-6379 (Online), vol.9, no.5, May (2016), pp. 157-174.

[8] K.H.S Sabaragamu Koralalage, "Where the POP Architecture Stands among the other RFID Solutions was recalled by author because authors found some critical problems", International Journal of Security and Its Applications, NADIA, ISSN: 1738-9976 (Print); 2207-9629 (Online), vol.3, no.1, January (2009), pp. 65-76.

[9] Jitendra Singh Sengar, Richa Sharma, "Review: Ad-Hoc Cloud Architecture \& Modern Cryptography", International Journal of Grid and Distributed Computing, NADIA, ISSN: 2005-4262 (Print); 2207-6379 (Online), vol.9, no.6, June (2016), pp. 45-50.

[10] Xixu Fu, Kaijun Wu and XiZhang Gong, "Implement Access Control Architecture to Enhance Security and Availability of Cloud Computing Systems", International Journal of Security and Its Applications, NADIA, ISSN: 1738-9976 (Print);

[11] Popper, R., Keenan, M., Miles, I., Butten, M., and Fuenza, G. "Global Foresight Outlook 2007, EFMN " S27-7 (2009): 956

[12] Zeyu Sun, Yaping Li, Yangjie Cao, Yuanbo Li, "Evaluation Model Queuing Task Scheduling Based on Hybrid Architecture Cloud Systems", International Journal of Grid and Distributed Computing, NADIA, ISSN: 2005-4262 (Print); 2207-6379 (Online), vol.9, no.6, June (2016), pp. 169-180.

[13] Cong Liu, Xinyu Zhang, YiGang Diao and XinGang Wu, "Research on the Key Technologies of Base Station Server Content Delivery Based on Broadcast-Storage Architecture", International Journal of Grid and Distributed Computing, NADIA, ISSN: 2005-4262 (Print); 2207-6379 (Online), vol.9, no.7, July (2016), pp. 289-300.

[14] Javed Ahmad Shaheen, "Architecture of Task Manager for Real Time OS Explaining Real Time Operating Systems Issues", International Journal of Grid and Distributed Computing, NADIA, ISSN: 2005-4262 (Print); 2207-6379 (Online), vol.9, no.9, September (2016), pp. 395-402.

[15] Bea, Y.H., Korea Institute of Construction \& Transportation Technology Evaluation and Planning, "Development Performance Measurement for Construction Technology Research." (2009): 2-32. 1512

[16] Jeon Hwang-su. "Trends in the development of Auto-IT convergence technology in Korea and abroad, Korea Multimedia Society." Vol. 14 (2009).

[17] Kim Byeong-woo. "2010 Trends in auto-IT convergence technolog, Korea Information Processing Society." Vol. 16 (2009). 